\title{
Role of bee Venom Acupuncture in improving pain and life quality in Egyptian Chronic Low Back Pain patients
}

\author{
Aliaa El Gendy ${ }^{1}$, Maha M. Saber ${ }^{1}$, Eitedal M. Daoud ${ }^{1}$, Khaled G. Abdel-Wahhab ${ }^{2}$, Eman Abd el-Rahman ${ }^{3}$, \\ Ahmed G. Hegazi ${ }^{*}$ \\ ${ }^{1}$ Complementary Medicine Department, National Research Centre, Giza, Egypt. \\ ${ }^{2}$ Medical Physiology Department, National Research Centre, Giza, Egypt. \\ ${ }^{3}$ Parasitology Department, National Research Centre, Giza, Egypt. \\ ${ }^{4}$ Zoonotic Diseases Department, National Research Centre, Giza, Egypt.
}

\begin{tabular}{|c|c|}
\hline ARTICLE INFO & ABSTRACT \\
\hline $\begin{array}{l}\text { Article history: } \\
\text { Received on: } 26 / 01 / 2017 \\
\text { Accepted on: } 07 / 04 / 2017 \\
\text { Available online: } 30 / 08 / 2017\end{array}$ & $\begin{array}{l}\text { Chronic non-specific low back pain is considered to be the commonest medical symptom for which patients } \\
\text { seek complementary and alternative medical treatment, including bee venom acupuncture. This study was done } \\
\text { to detect the effect of bee venom acupuncture (BVA) for controlling of chronic low back pain (CLBP). We } \\
\text { compared the effects of BVA on } 40 \text { patients with CLBP, pre-and post-treatment. The age of patient ranged from }\end{array}$ \\
\hline $\begin{array}{l}\text { Key words: } \\
\text { Chronic low back pain, } \\
\text { Apitherapy, Bee venom, } \\
\text { Cytokines. }\end{array}$ & $\begin{array}{l}\text { analog scale (VAS), Oswestry Disability Index (ODI), serum levels TNF } \alpha \text {, IL1 } 1 \beta \text {, IL-6, and NF-KB as well as } \\
\text { ESR before and after BVA treatment. The obtained results revealed that the application of BVA ameliorated the } \\
\text { disturbances induced by CLBP, as it showed a significant improvement in VAS }(65 \%) \text { accompanied with a } \\
\text { significant improvement in ODI }(75.6 \%) \text { in all patients. Moreover, BVA treatment resulted in a significant } \\
(\mathrm{p}<0.05) \text { amelioration in serum level of TNF } \alpha(-14 \%) \text {, IL1 } \beta(-52 \%) \text {, IL-6 }(-53 \%) \text { and NFKB }(-32.6 \%) \text { and ESR } \\
(-39.8 \%) \text {. From the mentioned findings, it could be concluded that BVA performed an improvement in CLBP } \\
\text { patients, regarding pain intensity, disability and quality of life supported with improvement in serum levels of } \\
\text { TNF } \alpha \text {, IL1 } \beta \text {, IL-6 and NF-KB and ESR. }\end{array}$ \\
\hline
\end{tabular}

\section{INTRODUCTION}

Chronic non-specific low back pain (CLBP) is a common medical problem characterized by being multifactorial where musculoskeletal pain and psychosocial factors interact with each other (Vereckei et al., 2013). CLBP can be defined as back pain that extend for more than 7-12 weeks (Dillon et al., 2004). Many studies have shown the high frequency of back complaints and 70-85\% of people have back pain at some time in life (Andersson, 1999). Patients with CLBP have increasingly been using complementary and alternative medicine (CAM) to improve their symptom, despite of variable accessibility of

\footnotetext{
* Corresponding Author

cell phone +201001440063 , Phone: +20237749222

Fax: + 20233370931 E. mail: ahmed @ ahmedhegazi.com
}

conventional treatments (Hughes et al., 2011). The use of CAM therapeutic modalities including, herbal medicine, acupuncture, herbal acupuncture, cupping and chiropractic manipulation has been increased (Grazio and Balen, 2011). Pharmaco-puncture therapy is a form of therapy derived from the conjunction of herbal medicine theory and meridian system (Lee, 1999).

Apitherapy is the medical use of honey bee products (honey, pollen, bee bread, propolis, royal jelly, apilarnil and bee venom). Bee venom therapy is the part of apitherapy which utilizes bee venom in the treatment of health problems (Hegazi et al., 2015). However, bee venom is a complex mix of a variety of proteins and peptides, some of which have strong immunogenic (Hegazi, 2009) and neurotoxic effects (Ali, 2012). Park et al. (2010) stated that bee venom therapy is used for treatment of many different autoimmune disorders including rheumatoid arthritis, lupus, scleroderma and MS (Hegazi et al., 2015). 
It is also used for a group of other diseases, including menstrual cramp, depression, varicose veins and skin conditions (Prado et al., 2010). BVA is one of the most frequently performed pharmacopuncture to improve cervical pain (Kim et al., 2013). Also, BVA is utilized for the treatment of acute ankle sprain, osteoarthritis, shoulder pain, post-stroke, low back pain and lumbar disc herniation (Lee et al., 2008). BVA involves injecting of purified and diluted bee venom into acupoints (Baek et al., 2006 and Hegazi, 2012). BVA exhibits many pharmacological actions including anti-cancer, anti-arthritic anti-inflammatory and analgesic effects (Lee et al., 2013). Most claims of apitherapy have not been proved to the scientific standards of evidence-based medicine and are anecdotal in nature (Hegazi, 2012). Thus, the main objective of this study was to evaluate the therapeutic effect of BVA as a complementary modality for controlling of CLBP.

\section{PATIENTS AND METHODS}

Forty female patients with chronic back pain were recruited from the attendants at the Complementary Medicine Clinic of the Medical Service Unit, National Research Centre, Egypt, during the period between March-August 2016. Before starting BVA treatment and as a screening process for eligibility, hypersensitivity test was performed on each patient by bee sting at GV14 acupoints. A local swelling greater than $10 \mathrm{~mm}$ in diameter or redness greater than $20 \mathrm{~mm}$ in diameter was considered a positive reaction; those patients were excluded from the study.

\section{Inclusion Criteria}

The criteria those were mostly included in this study were age of patients that ranged from 38-65 years; painful restriction of lumbar spine mobility that was more than 6 months; no treatment for 2 weeks prior the study; radiological examination was carried out of plain X-ray lumbo-sacaral spine both anterposteroir (AP), lateral views to diagnose and detect degenerative changes; and MRI to rule out surgical causes of back pain. Patients must be $\geq 3$ points on a 10 -cm VAS scale at the time of screening.

\section{Exclusion Criteria}

Diabetes mellitus, neurological deficits, rheumatoid arthritis, ankylosing spondylitis, organ failure, cancer, and previous history of surgery in the back or dislocation or fracture, chief musculoskeletal pain other than back pain were excluded in this investigation. Conditions for which administration of BVA might not be safe including clotting disorders, administration of an anticoagulant agent, pregnancy and seizure disorders, a documented hypersensitive reaction to previous BVA treatments; bee stings or insect bites, a positive reaction observed during a hypersensitivity test, a severe psychiatric or psychological disorders, current use of corticosteroids, narcotics, muscle relaxants or herbal medicines to treat back pain or any medication considered inappropriate by the investigator. The selected CLBP patients were subjected to BVA treatment in the form of bees' stinging at standard acupoints (GB30, BL25, BL26, BL40, BL37,
BL57, GB34, GV3, ST36 and LIV3) according to Traditional Chinese. All procedures, including the bee venom acupuncture increment protocol administered into predefined acupoints, are designed by a process of consensus with experts and previous researchers according to the standards for Reporting Interventions in Clinical Trials of Acupuncture (STRICTA) (MacPherson et al., 2010) and Medical Ethics Committee, National Research Centre, Egypt, where each patient received 2 sessions weekly for 6 weeks.

\section{Allowance of Concurrent Treatment of Patients}

During the study period, all other interventions, drugs and treatments for back pain were prohibited including surgical procedures, injections, acupuncture, physical therapy or the use of muscle relaxants, narcotics and analgesics. Regular medications not intended to affect back-pain related dysfunction were allowed. Any change in concurrent treatment was recorded at every visit. Medical history and socio demographic characteristics, including age, gender, marital status, residence and, occupation as well as education level were recorded from the screening visit. Any unpredicted, adverse events also were recorded at each visit. For all patients experiencing LBP lasting for at least the previous six months, the pain intensity of LBP was assessed using VAS $10 \mathrm{~cm}$ a fast and straightforward method for evaluating the subjective degree of pain intensity (Carlsson, 1983). Participants were asked to report the degree of pain intensity using the $10 \mathrm{~cm}$ VAS ( 0 , absence of pain; 10, the worst pain imaginable. Also, back pain related dysfunction was assessed using the Oswestry Disability Index questionnaire (ODI) that contains 10 questions about daily activities, including inventories of pain intensity, personal care, lifting, walking, sitting, standing, sleeping, social life, travelling and sexual life (was excluded). Each question was rated on a scale from zero to 5 points; the lower the score, the less disabled (Roland and Morris, 1983). The pain VAS and ODI were assessed at baseline and after 6 weeks of the end of the study.

\section{Safety}

All adverse events and vital signs were observed and reported. Liver \& renal functions of each participant were assessed before the treatment and one week after the end of treatment.

\section{Withdrawal and Dropout}

Participation in the study will end at any stage if the patient refuses to continue, withdraws consent, violates inclusion or exclusion criteria or the trial protocol, or completes less than four treatment sessions as determined by the attending researchers. The trial will be stopped if the principle investigator believes that there are unacceptable risks of serious adverse events.

\section{Laboratory Analysis}

Before and after treatment with BVA, blood samples $(5 \mathrm{ml})$ were withdrew from each patient. A part $(2 \mathrm{ml})$ from each whole blood sample was used in determination of erythrocyte sedimentation rate (ESR), while the other part $(3 \mathrm{ml})$ was left to coagulate then centrifuged at $300 \mathrm{rpm}$, the sera were separated into 
aliquots and stored at -70 till the determination of the TNF $\alpha$, IL1 $\beta$, IL6 and $\mathrm{NF}_{\mathrm{K}} \mathrm{B}$ using ELISA (enzyme linked immunosorbent assay) technique as soon as possible. Serum TNF $\alpha$, IL1 $\beta$ and IL6 levels were determined using human ELISA reagent kits purchased from Assaypro, Charles, MO 63301-4046, USA, while serum $\mathrm{NF}_{\mathrm{K}} \mathrm{B}$ level was estimated using human ELISA reagent kits purchased from Glory Science Co., Ltd, 2400 Veterans Blvd.Suite 16-101, Del Rio,TX78840,USA.

\section{Statistical Analysis}

As the same group patients was assigned to one specific treatment condition, the data were analyzed using One-Way ANOVA followed by Tukey's test using statistical analysis system (SAS) program software; copyright (c) 1998 by SAS Institute Inc., Cary, NC, USA. Unpaired t-test was used for comparison and determining the significance level. Differences were considered statistically significant when the probability of type I error was less than 0.05 .

\section{RESULTS}

Investigations suggested diabetes mellitus in 10 patients among the chosen 50 patients with CLBP; consequently, they were excluded out of this study, therefore only 40 CLBP female patients aged between $38-65$ years were included in the trial. All of them completed the study period.

The baseline demographic characteristics of the patients of our study recorded an age range between 38-65years with average of 50 years; the disease duration was from 1 to 5 years with mean of 2.56 years; the weights of those patients ranged between $61-122 \mathrm{~kg}$ with an average of $80.0 \mathrm{~kg}$; their heights were between $146-168 \mathrm{~cm}$ with average of $155.5 \mathrm{~cm}$ and the body mass index (BMI) of them ranged between 25-52 with average value 32.99 (Table 1).

In comparing with the values of VAS and ODI of the patients before bee stinging, the obtained data of both VAS and all items of ODI, after exposing the CLBP patients to BVA, showed a significant improvement at $p<0.0001$ level; while lifting recorded a significant reduction at $\mathrm{p}<0.05$ level (Table 2).

In addition, BVA treatement resulted in a significant improvement in the immunological status that achieved from the reduction in serum inflammatory cytokines; as there was a significant $(\mathrm{p}<0.05)$ decrease in serum TNF $\alpha(-14 \%)$, IL1 $\beta(52 \%)$, IL6 $(-53 \%)$ and $\mathrm{NF}_{\mathrm{K}} \mathrm{B}(-32.6 \%)$ matched with a significant $(\mathrm{p}<0.05)$ reduction in $\operatorname{ESR}(-39.4 \%)$ in compare to the corresponding values before treatment (Figures 1 and 2).

Table 1: Demographic characteristics of patients with CLBP included in study.

\begin{tabular}{lll}
\hline Parameters & Range & Mean \pm SD. \\
\hline Age / years & $38-65$ & $50.9 \pm 6.22$ \\
Disease duration/ years & $1-5$ & $2.65 \pm 1.31$ \\
Weight /Kg & $61-122$ & $80.83 \pm 14.81$ \\
Hight /cm & $146-168$ & $155.45 \pm 4.8$ \\
BMI (body mass index) & $25.5-52$ & $32.99 \pm 6.03$ \\
\hline
\end{tabular}

The data of all patients are expressed as mean \pm standard deviation
Table 2: Mean of VAS and all items of ODI of patients with CLBP pre- and post treated with BVA.

\begin{tabular}{llllll}
\hline & Before & After & \% improve p value & \\
\hline VAS & $8.35 \pm 1.31$ & $2.9 \pm 1.77$ & 65.27 & $<0.0001$ & sig \\
PI & $2.80 \pm 0.95$ & $0.45 \pm 0.51$ & 83.93 & $<0.0001$ & sig \\
PC & $2.0 \pm 0.56$ & $0.35 \pm 0.48$ & 82.50 & $<0.0001$ & sig \\
Lifting & $1.85 \pm 1.08$ & $1.15 \pm 0.88$ & 37.84 & $<0.05$ & sig \\
Walking & $2.40 \pm 0.75$ & $0.75 \pm 0.78$ & 68.75 & $<0.0001$ & sig \\
Sitting & $2.65 \pm 0.81$ & $0.30 \pm 0.47$ & 88.68 & $<0.0001$ & sig \\
Standing & $3.35 \pm 0.18$ & $2.94 \pm 0.17$ & 12.24 & $<0.0001$ & sig \\
Sleeping & $3.05 \pm 1.27$ & $0.75 \pm 0.96$ & 75.41 & $<0.0001$ & sig \\
Social & $2.35 \pm 0.87$ & $0.45 \pm 0.61$ & 80.85 & $<0.0001$ & sig \\
Travelling & $2.95 \pm 1.23$ & $0.55 \pm 0.60$ & 81.36 & $<0.0001$ & sig \\
Total & $23.4 \pm 5.4$ & $5.70 \pm 3.89$ & 75.64 & $<0.0001$ & sig \\
\hline
\end{tabular}

Data are expressed as mean \pm standard deviation.
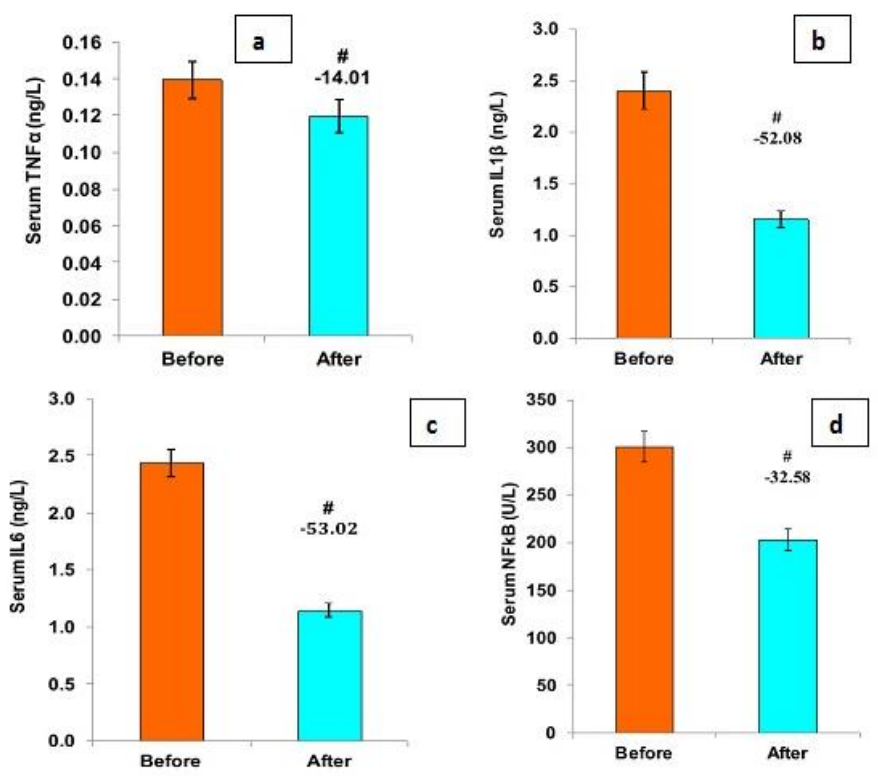

Fig. 1: Shows the effect of BVA treatment on serum level of TNF $\alpha$ (a), IL1 $\beta$ (b), IL6 (c), and $\mathrm{NF}_{\mathrm{K}} \mathrm{B}$ (d) of CLBP patients.

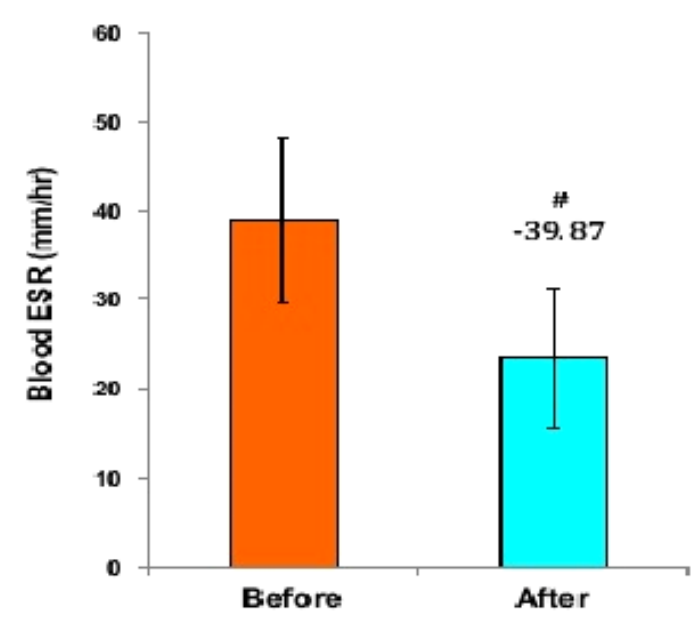

Fig. 2: Shows the effect of BVA treatment on level of ESR of CLBP patients. 


\section{DISCUSSION}

In order to choose the CAM therapy to a part for treatment in a various conditions, it is important to consider the relevant problem such as: curability of the illness by conventional treatment, degree of adverse effect, toxicities, invasiveness of conventional treatment, also safety, availability and quality of desired CAM treatment (Adam et al., 2002). The results from our study may be a good evidence for the effectiveness and safety of BVA on CLBP as an adjunctive to conventional therapy. In addition, it can be provided as clinical evidence regarding whether BVA can be beneficial in improvement of disease related functional status and daily life activity for the patients. Safety intervention is important for estimating its risk-benefit framework. In this study, VAS and all items of ODI Q were significantly improved post intervention with BVA; these improvements could be attributed to the antioxidative potential of BVA injection that significantly reduced the level of reactive oxygen species (ROS) and activity of proteolytic enzyme leading to inhibition of free radical responsible for damage of synovial fluid proteins (Kim et $a l .$, 2002). Our finding is in agreement with that of (Shin, 2011) who reported that VAS was significantly reduced in BV-treated patients group and controlled the early pain compared to acupuncture treated group. Lee et al., (2011) suggested that BVA has been reported to have anti-inflammatory and analgesic effects; thus, BVA is applied to treat painful diseases and musculoskeletal diseases such as lumbar spinal stenosis, herniation of an intervertebral disc, arthritis, neuralgia, myofascial pain syndrome and frozen shoulder; this study positively supported our results for using BVA to alleviate pain in chronically complaining patients and improving their quality of life .The analgesic antiinflammatory effect of BVA has been proven in several animal arthritic models (Jae-Dong et al., 2005). BVA injection at acupoint B1 23 significantly reduced the level of reactive oxygen species (ROS) and proteolytic enzyme activity as these free radical leads to damage of synovial fluid proteins in a rat inducing arthritis by a mixture of type II collagen (Kim et al., 2002). Bee venom at acupoint GB 34 was found to decrease the numbers of white blood cells, infiltration of fibroblasts and leukocytes into synovial joints, IL-1B, IL-2R, CD56, CD54 and CD 106 in synovial membrane when compared with controls in lipopolysaccharide- induced arthritis in rat model (Do et al., 2001). Stimulation of ST36 acupoint by BVA can decrease chronic constrictive injury of sciatic nerve-induced neuropathic pain by activation of $\alpha$ adrenoceptros, but not through opioid receptors (Roh et al., 2004). Also, Tsai et al., (2015) suggested that BV injection at a certain acupoints (LI4, SI3, KI3, ST36, BL23, BL40, CB30, GB34, LR3, unilateral GV1) can enhance treatment of canine neurological dysfunction by intervertebral disk disease.

From the previous studies, the difference in the mechanism between acupuncture and bee venom acupuncture therapy can be monitored, as acupuncture is one of the commonest treatment modalities to treat several chronic inflammatory diseases like osteoarthritis, rheumatoid arthritis,
(Ezzo et al., 2001 and Berman et al., 2002), neuropathic postoperative pain and low back pain (Han et al., 2010 and Joaquim et al., 2010) also it can trigger the release of endogenous endorphins, dynorphins, encephalin (Kim et al., 2009) as well as it can stimulate the noradrenergic inhibitory systems (Zhang et al., 2004, Koo et al., 2008 and Kim et al., 2011); while BVA has been reported to attenuate neuropathic pain system through activation of $\alpha$-adrenergic receptors, but not opioid receptors (Kang et al., 2012). However, Chen and Lariviere (2010) considered that BV having nociceptive and anti-nociceptive effects together this is called a "double-edged sword'. Also, other descending inhibitory systems like GABA, serotonergic and/or cholinergic systems might be involved (Kim et al. 2005, Kim et al., 2005 and Park et al., 2009). BV injections can cause the adrenal gland cortex and pituitary gland to increase the concentration of cortisol (Knepel and Gerhards, 1987 and Vick and Shipman, 1972). Several studies suggested that the effects of BVA depend on the site of injection as the acupuncture points are more effective than non-acupoints. So, anti -nociceptive action of BV is only produced when BV is injected into a specific acupoint (Lee et al., 2001, Seo et al., 2003, Kim et al., 2003). Also, BVA exerts its action not only pharmacological but also mechanical function from acupuncture stimulation; it believed that BVA has been proposed as another approach for treatment rather than needle acupuncture (Lee et al., 2005), so we designed our study as the bee sting must be at a specific acupoints related to LBP according to traditional Chinese Medicine (TCM). The results of many studies give a good idea for applying this therapy as a clinical treatment for many conditions in human being (Lee et al., 2006). Kim and Song (2005) and An and Song (2007) those carried out on two groups of cervical pain patients, one group received electro-acupuncture and the other group received bee venom therapy; they suggested that the bee venom showed better results. Another more recently study (Gang et al., 2012) was done to compare bee venom pharmacopuncture therapy and acupuncture therapy in patients with cervical herniated intervertebral disc there was more improvement in VAS of bee venom group than acupuncture group. These two mentioned studies supported our findings. Kwon et al. (2001) designed an experiment to detect whether BVA is a clinically safe and effective method for decreasing pain in knee osteoarthritis patients compared to traditional needle acupuncture. They found that BVA group showed a better response for pain relieving than needle acupuncture group. We concluded from the results of these several randomized controlled trials studies that bee venom acupuncture is more effective in treatment of arthritis than acupuncture.

In a study carried out by Seo et al (2013) on 54 CLBP, patients were randomized into 2 parallel arms, one group received diluted BV acupuncture and other group received normal saline; they found that there was a significant improvement in VAS and ODI in BV acupuncture group than saline or sham group. Same as our results that also showed BVA is effective in reducing VAS and ODI. It was stated that specific immunotherapy with bee venom can cause a nearly complete protection against allergic reactions from stings in most of patients (Severino et al. 2008). According 
to Janik et al., (2007) who found that bee venom was administered in the form of injection of a venom extract or a direct bee sting the same as design twice a week. It is claimed that bee venom therapy works with the patient's own body to decrease level of inflammation, as the stings produce inflammation; the body mounts an anti-inflammatory response (Park et al., 2010 and Prado et al.,2010)

The major component of BV was found to suppress inflammation by decreasing phospholipase (PLA) enzymatic activity is melittin (Saini et al., 1997) that is why the cytokines levels (TNFa, IL1ß, IL6 and NFאB) were reduced after stinging the patients with $\mathrm{BV} . \quad \mathrm{NF}_{-} \mathrm{B}$ is one of the most important regulators of expression of pro inflammatory genes such as $\mathrm{COX}_{2}$, and TNF $\alpha$ (Jeon et al., 2000 and Surh et al., 2001). BV or melittin has a potent anti-inflammatory effect through inhibition of the DNA binding activity of $\mathrm{NF}_{-} \mathrm{B}$ by inhibition of $\mathrm{I}_{\mathrm{K}} \mathrm{B}$ phosphorylation,leading to decrease of P50 translocation, resulting in reduction of inflammatory gene expression (Hye et al., 2004) this can explain the reducing potential of BVA on serum level of $\mathrm{NF}_{-\mathrm{K}} \mathrm{B}$ which in its turn down regulating TNF $\alpha$. That is an important mechanism of the anti-arthiritic effect of BV In this study, the serum levels of TNF $\alpha, \mathrm{NF}_{-\mathrm{K}} \mathrm{B}, \mathrm{IL}-1 \beta$ and IL- 6 , after 6 weeks of BVA, recorded a significant improvement compare to their values before BVA therapy. This result is in agreement with the results of Martins et al., (2011) who suggested that ten of the thirteen cytokines were significantly different between control and patients subjects. In this study, there was a statistically significant improvement in patients regarding their health, general conditions as well as their immunity in particular modulation of the immune system, and this is in agreement to that explained by (Son et al., 2007, Park et al.,2010).

Concerning the correlation between non-specific low back pain and raised titers of inflammatory cytokines and other non-specific immunological responses, IL-23 was significantly increased in chronic low back pain patients as proved by Luchting et al. (2014). Moreover, Cheng et al. (2015) reported that exercise intervention, the most effective back pain treatment, enhances expression of Sirtuin 1 and up-regulates the expression of peroxisome proliferator-activated receptor-gamma, PPAR- $\gamma$ coactivator-1 and FoxOs family proteins and also increases the activity of catalase and superoxide dismutase compared to untreated patients.

\section{CONCLUSION}

There is concerned about the extra cost of BVA; it considers as the cheapest mode for therapy from an economic point of view. In order to widespread the clinical therapeutic field of BVA around the world, rigorous trials of well-organized design are urgently required to detect its role in treatment of arthritis. Understanding of advantage and risks of BVA is also required. However, the quality of the studies and the number of subjects has been limited; BVA is considered to be a highly promising tool for treatment of chronic arthritis.
From the results, it could be concluded that bee venom therapy could be a potential new therapeutic agent in the treatment of low back pain patients, with minimal tolerable side effects. Interleukin-1 $\beta$, IL6, $\mathrm{NF}_{\mathrm{k}} \beta$ and TNF $\alpha$ gave an idea about mechanism of action and chemical changes occurring with BVA. This work is considered a possible starting point for further larger studies with wider scales of applications to confirm our findings.

\section{ACKNOWLEDGEMENTS}

Financial support and sponsorship: The authors are grateful for the financial support by the National Research Center of Egypt.

Conflict of Interests: There are no conflicts of interest.

\section{REFERENCES}

Adam KE, Cohen ME, Eisenberg D, Jonsen AR. Ethical Considerations of Complementary and Alternative Medical Therapies in Conventional Medical Settings. Ann Intern Med, 2002; 137:660-4.

Ali M A M. Studies on Bee Venom and Its Medical Uses. International Journal of Advancements in Research and Technology, 2012;1, (2):69-83.

An BJ, Song HS. Effect of bee venom acupuncture therapy on patients with cervical spondylosis] The Acupuncture. 2007; 24(3):111117.

Andersson GB. Epidemiological features of chronic low-back pain. Lancet, 1999; 14;354(9178):581-5.

Baek YH, Huh JE, Lee JD, Choi DY, Park DS. Antinociceptive effect and the mechanism of bee venom acupuncture (Apipuncture) on inflammatory pain in the rat model of collagen-induced arthritis: Mediation by alpha2-Adrenoceptors. Brain Res, 2006; 1073-1074:305-10.

Berman BM, Swyers JP, Ezzo J. The evidence for acupuncture as a treatmentfor rheumatologic conditions. Rheum Dis Clin North Am, 2000; 26:103-15.

Carlsson AM. Assessment of chronic pain. I. Aspects of the reliability and validity of the visual analogue scale. Pain, 1983;16:87-101.

Chen J. and Lariviere W. R. The nociceptive and antinociceptive effects of bee venom injection and therapy: a doubleedged sword. Progress in Neurobiology, 2010; 92, (2): 151-183,.

Cheng YY, Kao CL, Ma HI, Hung CH, Wang CT, Liu DH, Chen PY, Tsai KL. SIRT1-related inhibition of pro-inflammatory responses and oxidative stress are involved in the mechanism of nonspecific low back pain relief after exercise through modulation of Tolllike receptor 4. J Biochem, 2015;158, (4):299-308.

Dillon C, Paulose-Ram R, Hirsch R, Gu Q : Skeletal muscle relaxant use in the United States : data from the Third National Health and Nutrition Examination Survey (NHANES III). Spine (Phila Pa1976), 2004; 29: 892-896.

Do WS, Kim KH, Kim KS. Effects of aqua-acupuncture (Cortex Pumilae, Ramulus Cinnamomum, Radix Achyranthis, Apitoxin, Calculus Bovis, Fel Ursi, Moschus compound) in mice with lipopolysaccharide. J Kor Acu Mox Soc, 2001;18:157-69.

Ezzo J, Hadhazy V, Birch S. Acupuncture for osteoarthritis of the knee: asystematic review. Arthritis Rheum, 2001;44:819-25.

Gang JH, Jo E, Lee H. [The retrospective comparative study of bee venom pharmacopuncture therapy in patients with cervical herniated intervertebral disc] The laboratory of Daejeon University Oriental Medicine, 2012; 20(2):117-124.

Grazio S, Balen D. Complementary and alternative treatment of musculoskeletal pain. Acta Clin Croat, 2011;50:513-530.

Han HJ, Yoon HY, Kim JY, Jang HY, Lee B, Choi SH, Jeong SW. "Clinical effect of additional electroacupuncture on thoracolumbar 
intervertebral disc herniation in 80 paraplegic dogs, Am J Chin Med. 2010;38(6):1015-25.

Hegazi A. G., Al-Menabbawy K., Rahman E. H. and Helal S.I. Novel therapeutic modality of Apitherapy for controlling of Multiple Sclerosis. Journal of Clinical and Cellular Immunology. Journal of Clinical and Cellular Immunology, 2015: 6:1.

Hegazi AG. Medical importance of bee products. ARI BİLIMİ / BEE SCIENCE, 2012; 12(4): 136-146.

Hegazi, Role of cytokines in bee venom therapy - Part I. Apitherapy Review, 2009; Issue 3

Hughes CM, Quinn F, Baxter GD. Complementary and alternative medicine: perception and use by physiotherapists in the management of low back pain. Complement Ther Med, 2011;19 (3):14954.

Janik J, Wania-Galicia L, Kalauokalani D. Bee stings a remedy for postherpetic neuralgia? A case report. Reg Anesth Pain Med, 2007; 32: $533-535$

Jeon YJ, Kim YK, Lee M, Park SM, Han SB, Kim HM. Radicicol suppresses expression of inducible nitric-oxide synthase by blocking p38 kinase and nuclear factor- $\mathrm{\kappa B} / \mathrm{Rel}$ in lipopolysaccharidestimulated macrophages. J Pharmacol Exp Ther, 2000; 294: 548-54.

Joaquim J G F, Luna S. P. L., Brondani J. T., Torelli S. R., Rahal S. C., and Freitas. PDe. Comparison of decompressive surgery, electroacupuncture, and decompressive surgery followed by electroacupuncture for the treatment of dogs with intervertebral disk diseasewith long-standing severe neurologic deficits," Journal of the American Veterinary Medical Association, , 2010; 236 (11): 225-1229.

Kang SY, Roh DH, Yoon SY Moon JY, Kim HW, Kang H, Roh SY, Yoon D H, Moon SY, Kim JY, Lee HW, Kim HJ,Wang HY, Lee J, Kim I, Chung HK, and Chung JM. Repetitive treatment with diluted bee venom reduces neuropathic pain via potentiation of locus coeruleus noradrenergic neuronal activity and modulation of spinal NR1 phosphorylation in rats," Journal of Pain, 2012; 13 (2): 155-166.

Kim HY, Wang J, Lee I, Kim HK, Chung K, Chung JM. Electroacupuncture suppresses capsaicin-induced secondary hyperalgesia through an endogenous spinal opioid mechanism. Pain. 2009;145(3):332340

Kim HW, Kwon YB, Han HJ, Yang IS, Beitz AJ, Lee JH.Antinociceptive mechanisms associated with diluted bee venom acupuncture (apipuncture) in the rat formalin test: involvement of descending adrenergic and serotonergic pathways. Pharmacol Res, 2005;51(2):183-8.

Kim HW, Kwon YB, Ham TW, Roh DH, Yoon SY, Lee HJ, Han HJ, Yang IS, Beitz AJ, Lee JH. Acupoint stimulation using bee venom attenuates formalin-induced pain behavior and spinal cord fos expression in rats. J Vet Med Sci. 2003;65(3):349-55.

Kim JH, Kim HY, Chung K, and Chung JM. Electroacupuncture reduces the evoked responses of the spinal dorsal horn neurons in ankle-sprained rats, Journal of Neurophysiology, 2011;105 (5): 2050-2057.

Kim KH, Kim YR, Noh SH, Kang KW, Kim JK, Yang GY, Lee BR. Use of acupuncture for pain management in an academic Korean medicine hospital: a retrospective review of electronic medical records. Acupunct Med, 2013;31:228-234.

Kim KT, Song HS. A randomized controlled double blinding study of bee venom acupuncture therapy on sprain of C-spine. The Acupuncture, 2005;22(4):189-195.

Kim MJ, Park SD, Lee AR, Kim KH, Jang JH, Kim KS. The effect of bee venom acupuncture on protease activity and free radical damage in synovial fluid from collagen-induced arthritis in rats. J Kor Acu Mox Soc, 2002;19:161-75.

Kim SK, Park JH, Bae SJ, Kim JH, Hwang BG, Min BI, Park DS, Na HS. Effects of electroacupuncture on cold allodynia in a rat model of neuropathic pain: mediation by spinal adrenergic and serotonergic receptors. Experimental neurology, 2005;195(2):430-436.

Knepel W. and Gerhards C. Stimulation by melittin of adrenocorticotropin and beta-endorphin release from rat adenohypophysis in vitro, Prostaglandins, 1987;33 (3): 479-490.
Koo S. T., Lim K. S., Chung K., Ju H., and Chung J. M. Electroacupuncture-induced analgesia in a rat model of anklesprain pain is mediated by spinal $\alpha$-adrenoceptors. Pain, 2008; 135 (1-2): 11-19.

Kwon YB, Kim JH, Yoon JH, Lee JD, Han HJ, Mar WC, Beitz AJ, Lee JH. The analgesic efficacy of bee venom acupuncture for knee osteoarthritis: a comparative study with needle acupuncture. Am J Chin Med. 2001;29(2):187-99.

Kwon YB, Lee JD, Lee HJ, Han HJ, Mar WC, Kang SK, Beitz AJ, Lee JH. Bee venom injection into an acupuncture point reduces arthritis associated edema and nociceptive responses. Pain, 2001; 90(3): 271-80.

Lee -D, Park HJ, ChaeY and Lim S. An Overview of Bee Venom Acupuncture in the Treatment of Arthritis eCAM, 2005; 2 (1): $79-84$

Lee HJ. Pharmacopuncture introduction and clinical theory. IlJeung; Seoul: 1999. pp. 13-15.

Lee JA, Son MJ, Choi J, Yun KJ, Jun JH, Lee MS.Bee venom acupuncture for rheumatoid arthritis: a systematic review protocol BMJ Open, 2014; 4(4):e004602.

Lee JY, Han YJ, Kim JH, Kim YJ, Kwon KR. [Type analysis of pharmacopuncture papers published in the journal of korean institute of pharmacopuncture] J Pharmacopunct, 2006; 9(3):147-154.

Lee KH, Cho YY, Kim S, Sun SH. History of Research on Pharmacopuncture in Korea. J Pharmacopuncture, 2016 ; (2):101-8.

Lee MS, Pittler MH, Shin BC, Kong JC, Ernst E. Bee venom acupuncture for musculoskeletal pain: a review. J Pain, 2008; 9(4):289-97.

Luchting B, Rachinger-Adam B, Zeitler J, Egenberger L, Möhnle P, Kreth S, Azad SC. Disrupted TH17/Treg Balance in Patients with ChronicLow Back Pain. PLoS One. 2014;9(8):e104883.

MacPherson H, Altman DG, Hammerschlag R, Youping L, Taixiang W, White A, Moher D. Revised Standards for reporting interventions in clinical trials of acupuncture (STRICTA): extending the CONSORT statement. J Evid Based Med, 2010; 3:140-155.

Martins TB, Rose JW, Jaskowski TD, Wilson AR, Husebye D, Seraj HS, Hill HR. Analysis of proinflammatory and antiinflammatory cytokine serum concentrations in patients with multiple sclerosis by using a multiplexed immunoassay. Am $\mathrm{J}$ Clin Pathol. 2011;136(5):696-704.

Park HJ, Lee SH, Son DJ, Oh KW, Kim KH, Song HS, KimGJ, Oh GT, Yoon DY, and HongJT. Antiarthritic Effect of Bee Venom Inhibition of Inflammation Mediator Generation by Suppression of NF-B Through Interaction With the p50 Subunit. ARTHRITIS and RHEUMATISM, 2004; 50, (11): 3504-3515

Park J H, Kim SK., Kim HN, Sun B, Koo S., Choi SM, Bae H., and Min BI. Spinal cholinergic mechanism of the relieving effects of electroacupuncture on cold and warm allodynia in a rat model of neuropathic pain, The Journal of Physiological Sciences, ,2009; 59 ( 4): 291-298.

Park S, Chun HJ, Keum B, Seo YS, Kim YS, Jeen YT, Lee HS, Um SH, Kim CD, Ryu HS. Anaphylactic shock-induced ischemic proctocolitis following bee stings: first case report. Endoscopy. 2010;42 (2):E153-E154

Prado ST G, Lomonte B. Acute physiopathological effects of honeybee (Apis mellifera) envenoming by subcutaneous route in a mouse model. Toxicon, 2010; 56: 1007-1017.

Roh DH, Kwon YB, Kim HW, Ham TW, Yoon SY, Kang SY, Han HJ, Lee HJ, Beitz A J.and Lee JH. Acupoint stimulation with diluted bee venom (apipuncture) alleviates thermal hyperalgesia in a rodent neuropathic pain model: involvement of spinal alpha2adrenoceptors," Journal of Pain, , 2004; 5 (6):297-303.

Roland M, Morris R. A study of the natural history of back pain. Part I: development of a reliable and sensitive measure of disability in low-back pain. Spine. 1983;8:141-144.

Saini SS, Peterson JWand Chopra AK. Melittin binds to secretary phospholipase A2 and inhibits its enzymatic activity". Biochemical and Biophysical Research Communication, 1997; 238: 436442. 
Seo BK, Lee JH, Sung WS, Song EM, and Jo DJ. Bee venom acupuncture for the treatment of chronic low back pain: study protocol for a randomized, double-blinded, sham-controlled trial $\mathrm{J}$ Biomedcenter, $2013 ; 14: 3-8$.

Seo DM, Park DS, Kang SG. The analgesic effect of bee venom aquaacupuncture and its mechanism in the rat model with adjuvantinduced arthritis. J Kor Acu Mox Soc, 2003;20:85-97.

Severino M G, Cortellini G, Bonadonna P, Francescato E, Panzini I, Macchia D, Campi P, Spadolini I, Canonica W G, Passalacqua 1. Sublingual immunotherapy for large local reactions caused by honeybee sting: A double-blind, placebo-controlled trial. Journal of Allergy and Clinical Immunology, 2008; 122(1): 44-48.

Shin YJ. [A clinical pilot study comparing sweet bee venom parallel treatment with only acupuncture treatment in patient diagnosed with lumbar spine sprain. J Pharmacopuncture. 2011;14(2):37-43.

Son DJ, Lee JW, Lee YH, Song HS, Lee CK, Hong JT: Therapeutic application of anti-arthritis, pain-releasing, and anti-cancer effects of bee venom and its constituent compounds. Pharmacol Ther, 2007; 115:246-270.

Surh YJ, Chun KS, Cha HH, Han SS, Keum YS, Park KK, et al. Molecular mechanisms underlying chemopreventive activities of antiinflammatory phytochemicals: down-regulation of COX-2 and iNOS through suppression of NF-kB activation. Mutat Res 2001; 480-481: 24368 .

Tsai LC, Lin YW, and Hsieh CL: Effects of Bee Venom Injections at Acupoints on Neurologic Dysfunction Induced byThoracolumbar Intervertebral Disc Disorders in Canines:A Randomized, Controlled Prospective Study BioMed Research Volume 2015, Article ID 363801, 7 pages http://dx.doi. org/10.1155/2015/ 363801 International
Vereckei E, Susanszky E, Kopp M, Ratko I, Czimbalmos A, Nagy Z, Palkonyai E, Hodinka L, Temesvari PI, Kiss E, Töro K, Poor G. Psychosocial, educational, and somatic factors in chronic nonspecific low back pain. Rheumatol Int., 2013; 33(3):587-92.

Vick J. A. and Shipman W. H. "Effects of whole bee venom and its fractions (apamin and melittin) on plasma cortisol levels in the dog," Toxicon, 1972;10 (4) 377-380.

Zhang S. P., Zhang J. S., Yung K. K. L., and Zhang H. Q. "Nonopioid- dependent anti-inflammatory effects of low frequency electroacupuncture," Brain Research Bulletin, 2004; 62 (4): 327-334.

\section{How to cite this article:}

Aliaa EL Gendy, Maha M Saber, Eitedal M Daoud, Khaled G Abdel-Wahhab ${ }^{2}$, Eman Abd el-Rahman ${ }^{3}$ and Ahmed G Hegazi., Role of bee Venom Acupuncture in improving pain and life quality in Egyptian Chronic Low Back Pain patients. J App Pharm Sci, 2017; 7 (08): 168-174. 